\title{
Evaluation of main factors affecting fractured horizontal well productivity of tight sand gas reservoir in Sichuan Basin
}

\author{
Linqing Liu ${ }^{1}$, Shuo Zhai ${ }^{2,}{ }^{*}$, HaiTao $\mathrm{Li}^{1}$, Jing Wang ${ }^{1}$ \\ ${ }^{1}$ Exploration and Development Research Institute of Petro China Southwest Oil \& Gas Field Company, Sichuan, China \\ ${ }^{2}$ Chengdu University of Technology, Sichuan, China
}

\begin{abstract}
Hydraulic fracturing horizontal well is the key technology of tight gas development. After fracturing, the gas well shows the characteristics of great difference in production energy and many factors affecting production capacity. Therefore, taking 10 fractured horizontal wells in JQ gas field in Sichuan Basin as an example, comprehensively considering the influence of geological and engineering factors, and based on the statistical analysis of gas well productivity and the laws of various index parameters, 17 geological and engineering parameters were selected, and the main factors controlling productivity were studied by grey correlation method. The results show that the tight gas fracturing horizontal well can obtain high production, which is jointly determined by geological and engineering factors. The five main control factors affecting the productivity of tight gas fracturing horizontal well are as follows: proppant type, preflush, $\phi \cdot h$. Sand volume and reservoir volume.
\end{abstract}

Keywords. Tight gas, fractured horizontal well, productivity, grey correlation method, main control factors.

\section{Introduction}

The world is rich in tight gas resources, with geological reserves of about $201 \times 1012 \mathrm{~m} 3$. With the progress of hydraulic fracturing technology, the production of tight gas is higher and higher, which occupies a more and more important position in the world energy pattern. However, The porosity, permeability and abundance of tight gas are lower than those of other gas reservoirs, hydraulic fracturing technology improves the productivity and economic benefits of tight gas wells, but there are many factors affecting productivity and it is difficult to evaluate productivity.

However, traditional theoretical methods and numerical simulation methods are difficult to evaluate and analyze the factors affecting production capacity. Based on the statistics of productivity influencing factors of 10 fractured horizontal wells in JQ gas field, Sichuan Basin, 17 engineering and geological parameters are analyzed by grey correlation method, and the main factors affecting the productivity of fractured horizontal Wells, namely productivity controlling factors, are obtained. Through this study, we have a better understanding of development sweet spots, sweet spots, fracturing and development mode formulation in tight areas.

\section{Productivity characteristics and influencing factors of gas wells}

Jinqiu gas field in Sichuan Basin is dominated by fractured horizontal wells, and the length of horizontal section is between 400-1200 meters. Multiple clusters of perforations and continuous sand addition process are adopted in the fractured section of horizontal wells. The productivity of Jinqiu gas field varies greatly. The minimum absolute open flow rate of single well is $1.14 \times 10^{4} \mathrm{~m}^{3} / \mathrm{d}$ and the maximum is $214.05 \times 10^{4} \mathrm{~m}^{3} / \mathrm{d}$. The relationship between geological parameters and open flow rate of gas well and engineering parameters and open flow rate of gas well are obtained according to the productivity data obtained from the test in the early stage of gas well production.

As shown in Figure 1, the absolute open flow of gas well has a strong positive correlation with reservoir thickness, $\phi \cdot h$, reservoir volume and pressure, so the physical properties of reservoir have a great impact on the productivity of gas well.

\footnotetext{
* Corresponding author: 2020050127@stu.cdut.edu.cn
} 


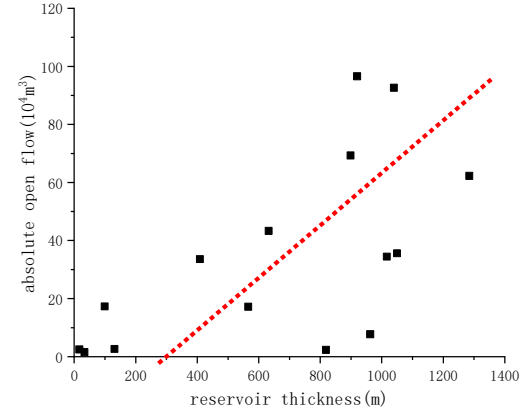

a. Relationship between absolute open flow and reservoir thickness

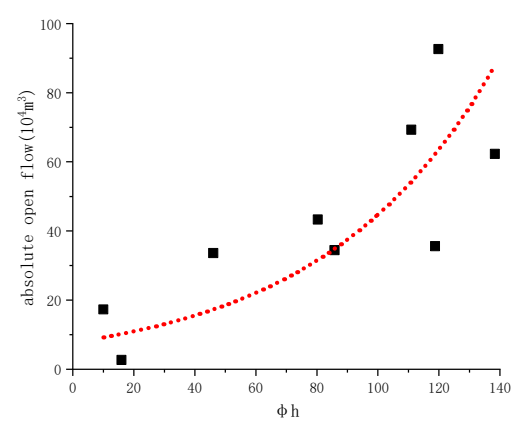

b. Relationship between absolute open flow and $\phi \cdot h$

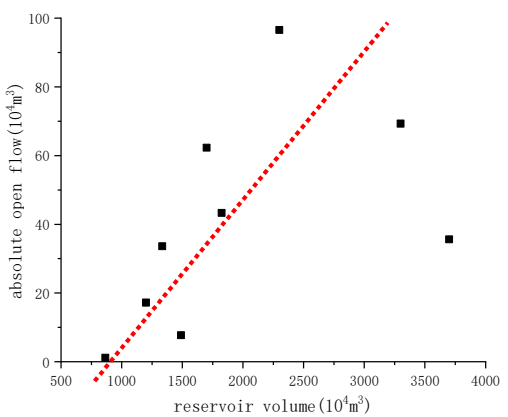

c. Relationship between absolute open flow and reservoir volume

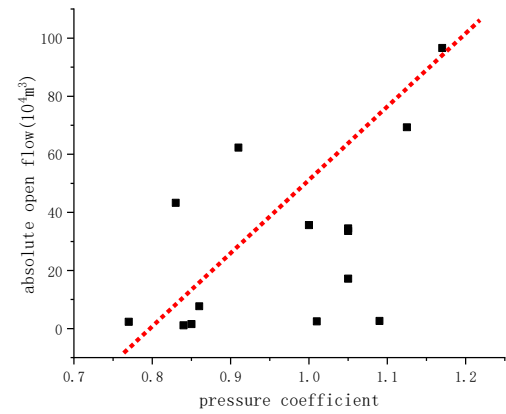

d. Relationship between absolute open flow and pressure coefficient

Figure 1. Relationship between absolute open flow of gas well and geological parameters

As shown in Figure 2, engineering parameters also have a certain positive correlation with absolute open flow of gas wells, and its influence trend is more complex than the relationship between geological parameters and absolute open flow.

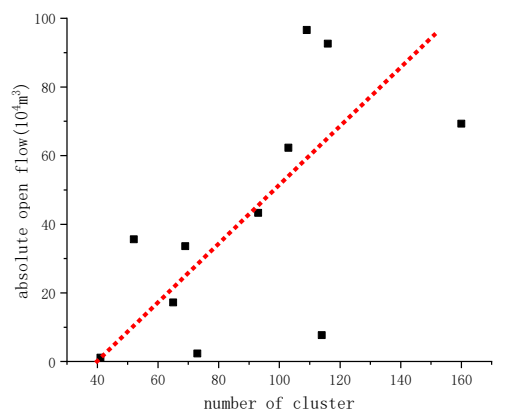

a. Relationship between absolute open flow and perforation number of cluster

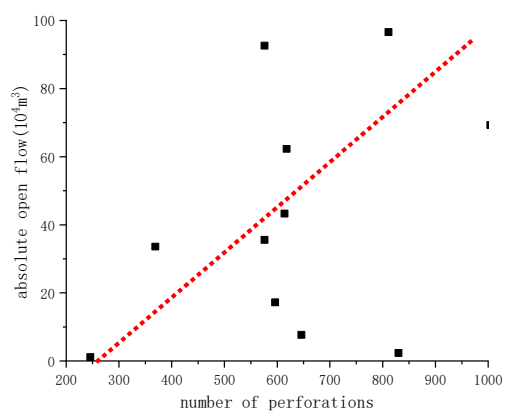

b. Relationship between absolute open flow and number of perforations

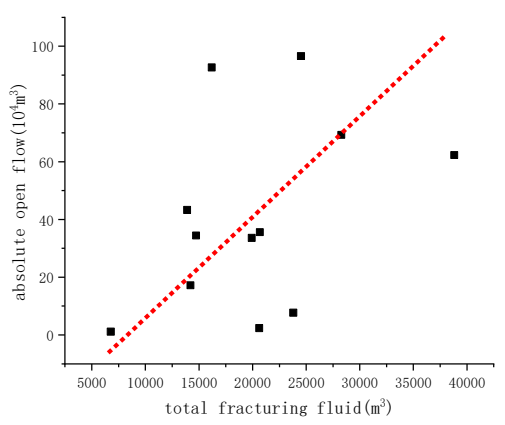

c. Relationship between absolute open flow and total fracturing fluid

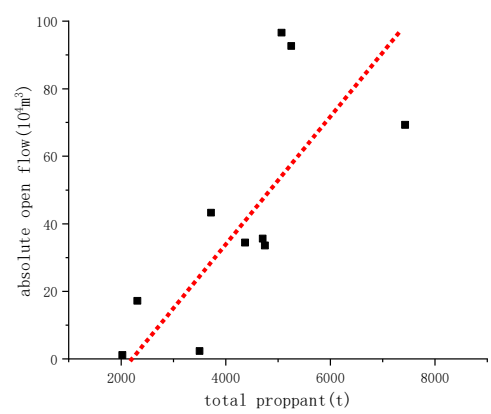

d. Relationship between absolute open flow and total proppant 


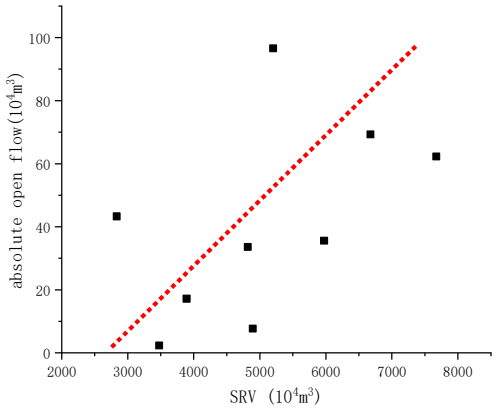

e. Relationship between absolute open flow and SRV

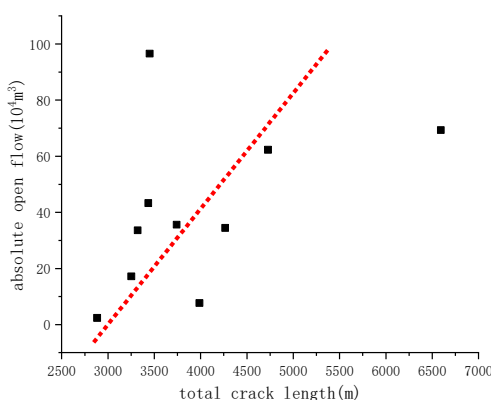

f. Relationship between absolute open flow and total crack length

Figure 2. Relationship between absolute open flow of gas well and engineering parameters

According to the statistical relationship between geological and engineering parameters and absolute open flow of gas wells, the productivity of fractured horizontal wells in tight gas reservoirs is comprehensively affected and restricted by many factors. It is very important for gas well drilling and gas reservoir efficient development to clarify the main controlling factors of productivity.

\section{Grey correlation analysis}

Grey correlation analysis method is an analysis method based on multi-factor comparison to get the main control factors, and the strength of correlation between factors is represented by grey correlation degree. The closer the change of grey correlation degree between two factors is, the stronger the correlation is. The geological parameters analyzed include porosity, permeability, water saturation, energy storage coefficient, pressure coefficient, reservoir thickness and reservoir volume; Engineering parameters are: number of clusters, number of perforations, amount of preflush, amount of sand carrying fluid, total amount of fracturing fluid, 70/140 proppant dose, 40/70 proppant dose, total amount of proppant, fracture length and SRV. The process is as follows:

(1) The invalid water injection ratio is selected as the reference sequence, and the geological and production parameters are the comparison sequence, expressed as (1);

$$
\left\{\begin{array}{l}
X_{0}=\left\{X_{0}(1), X_{0}(2), X_{0}(3), \ldots \ldots, X_{0}(n)\right\} \\
X_{i}=\left\{X_{i}(1), X_{i}(2), X_{i}(3), \ldots \ldots, X_{i}(n)\right\} \\
X_{m}=\left\{X_{m}(1), X_{m}(2), X_{m}(3), \ldots \ldots, X_{m}(n)\right\}
\end{array}\right.
$$

Where, $X_{0}$ - reference sequence; $X_{i}$ - comparison sequence; $\mathrm{j}=0,1,2 \ldots, \mathrm{m} ; \mathrm{k}=1,2, \ldots, \mathrm{n}$ 。

(2) In the process of grey correlation analysis, the influence of dimension and weight relation among all factors should be comprehensively considered. All factors should be unified in the same level and equal weight condition for calculation and analysis, and the dimensionless data should be carried out through the initial value method. First, select the optimal sequence and record it as $\left\{x_{0}^{\prime}(1), x_{1}^{\prime}(1), \mathrm{L} x_{n}^{\prime}(1)\right\}$. The calculation formula is:

$$
Y_{j}(k)=\frac{X_{j}(k)}{X_{j}^{\prime}(1)}
$$

Where, $\mathrm{Y}_{\mathrm{j}}(\mathrm{k})$ is the dimensionless sequence.

(3) Take the difference sequence:

$$
\Delta_{0 i}(k)=\left|Y_{0}(k)-Y_{i}(k)\right|
$$

Where, $\Delta_{0 i}(\mathrm{k})$ - absolute difference.

(4) Find the maximum and minimum difference of two levels:

$\Delta_{\max }=\max _{i} \max _{k}\left|Y_{0}(k)-Y_{i}(k)\right|$

$$
\Delta_{\min }=\max _{i} \max _{k}\left|Y_{0}(k)-Y_{i}(k)\right|
$$

Where, $\Delta_{\max }$-maximum difference of two stages; $\Delta_{\min }{ }^{-}$ minimum difference between two levels.

(5) The correlation coefficient is calculated as follows:

$\xi_{0 \iota}(k)=\frac{\Delta_{\min }+\rho \Delta_{\max }}{\Delta_{0 i}(k)+\rho \Delta_{\max }}$

Where, $\rho$-Resolution coefficient. Its function is to magnify the difference between correlation coefficients numerically, $\rho \in(0,1)$, usually $0.5, \rho$ The smaller the value, the greater the difference between the correlation coefficients. 


\section{Analysis results of main control factors}

According to the data of various influencing factors of fractured horizontal wells in JQ gas field, geological and engineering parameters are processed based on grey correlation analysis method, and the correlation degree comparison diagram of all factors of open flow can be obtained. As shown in FIG. 3, $\phi \cdot h$ has a great influence on reservoir volume and open flow. Among engineering factors, 70/140 mesh proppant, SRV, preconditioning fluid and open flow rate are the most important. Therefore, engineering factors are more influential than geological factors.

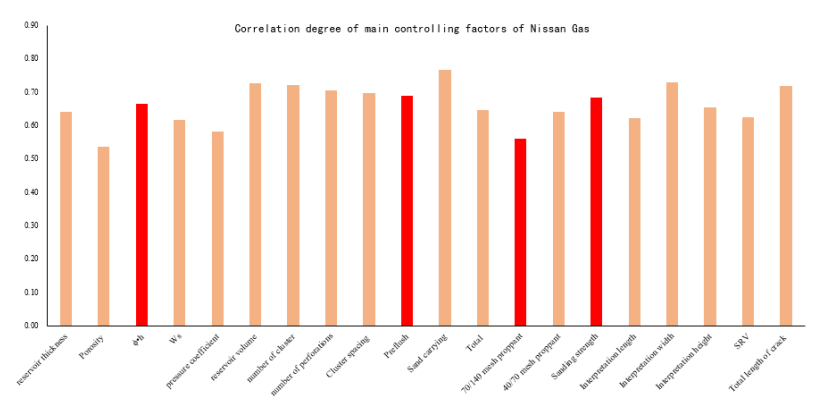

Figure 3. Main control factors of absolute open flow

\section{Analysis results of main control factors}

(1) There are 17 factors influencing the productivity of fractured horizontal Wells in tight gas. Based on the grey correlation analysis of these influencing factors, five main controlling factors are obtained, which are proppant type, pre-fluid, $\phi \cdot h$, sand volume and reservoir volume in order. (2) Whether tight gas wells can obtain high production is determined by geological and engineering factors, which complement each other. High reservoir quality is the material basis for shale gas wells to obtain high production, and high engineering quality is its technical guarantee.

\section{References}

1. $\mathrm{Fu}$ Jianbin. Productivity prediction method of fractured wells in tight gas reservoir considering multi factors[J]. Fault-Block Oil \& Gas Field, 2021,28(02):156-161.

2. Luo Hongwen, Li Haitao, An Shujie, et al. Analysis of Influencing Factors of Temperature Profile of Fractured Horizontal Wells in Tight Gas Reservoirs[J]. Special Oil \& Gas Reservoirs, 2021,28(04):150-157.

3. Duan Wenshen. Exploration potential and favorable direction of tight gas in Middle Jurassic Xiashaximiao Formation in Sichuan Basin[J]. Petroleum Geology \& Experiment, 2021,43(03):424431+467.

4. Deliang Zhang, Liehui Zhang, Yulong Zhao et al. A composite model to analyze the decline performance of a multiple fractured horizontal well in shale
reservoirs[J]. Journal of Natural Gas Science and Engineering, 2015, 26(C)

5. Liu Zixiong, Li Xiaonan, Wang Jinwei, et al. Study on method of sweet spot interval identification of tight gas reservoir in horizontal well[J]. China Petroleum Exploration, 2021,26(03):117-125.

6. Liang Xue, Shao-Hua Gu, Xie-Er Jiang, Yue-Tian Liu, Chen Yang. Ensemble-based optimization of hydraulically fractured horizontal well placement in shale gas reservoir through Hough transform parameterization $[\mathrm{J}]$. Petroleum Science, 2021,18(03):839-851.

7. HU Zubiao, ZHANG Jianqin, WANG Qingchen, et al. Water Base Drilling Fluid Technology for UltraLong Horizontal Drilling in a Tight Gas Well in Changqing Oilfield $[\mathrm{J}]$. Drilling Fluid \& Completion Fluid, 2021,38(02):183-188.

8. TANG Mingming, LU Shuangfang, LIANG Hongru, YAN Bihui, SHEN Shan. Study on the Fracturing Parameters and Productivity of Horizontal Wells[J]. Acta Geologica Sinica(English Edition), 2015, 89(S1):321-323.

9. LIU Naizhen, ZHANG Zhaopeng, ZOU Yushi, MA Xinfang, ZHANG Yinuo. Propagation law of hydraulic fractures during multi-staged horizontal well fracturing in a tight reservoir[J]. Petroleum Exploration and Development, 2018,45(06):11291138 .

10. WANG Lei, LIU Yingming, WANG Caizhi, FAN Yiren, WU Zhenguan. Real-time forward modeling and inversion of logging-while-drilling electromagnetic measurements in horizontal wells $[\mathrm{J}]$. Petroleum Exploration and Development, 2021, 48(01): 159-168. 